\title{
Effect of Learning Organization Culture on Organizational Performance Among Logistics Firms in Mombasa County
}

\author{
Gabriel Mrisha $^{1,}$, Mary Ibua $^{2}$, William Kingi ${ }^{1}$ \\ ${ }^{1}$ Department of Business Administration, Technical University of Mombasa, Mombasa, Kenya \\ ${ }^{2}$ Department of Management Science, Technical University of Mombasa, Mombasa, Kenya
}

Email address:

gmmtelian@gmail.com (G. Mrisha),mibua@tum.ac.ke (M. Ibua), wkingi@tum.ac.ke (W. Kingi)

${ }^{*}$ Corresponding author

\section{To cite this article:}

Gabriel Mrisha, Mary Ibua, William Kingi. Effect of Learning Organization Culture on Organizational Performance Among Logistics Firms in Mombasa County. Journal of Human Resource Management. Vol. 5, No. 2, 2017, pp. 32-38. doi: 10.11648/j.jhrm.20170502.11

Received: April 18, 2017; Accepted: May 2, 2017; Published: May 27, 2017

\begin{abstract}
This research was set to establish the effect of learning organization culture on the performance of Logistics firms in Mombasa County. The specific objectives of the study were to establish whether Individual level learning, team level learning and organization level learning affect organizational performance. A descriptive design was adopted and stratified random sampling was used to select the subjects to be included in the study. A total of 171 employees were sampled from a population of 300 employees. Questionnaires were used to collect primary data. Data was then analyzed using Pearson correlation coefficient and the relationship between was determined using regression analysis. The results were presented descriptively using frequency tables and pie charts. The study concluded that there exists a positive but weak relationship between continuous learning, collaboration and team learning and organizational performance. There was a positive but average relationship between employee empowerment and organizational performance while Inquiry and dialogue, embedded systems, systems connection and strategic leadership had a positive and strong relationship with organizational performance. The study concluded that learning organization culture significantly affects organizational performance.
\end{abstract}

Keywords: Learning Organization Culture, Individual Learning, Team Learning, Organizational Learning, Organizational Performance

\section{Introduction}

Increased emphasis on and examination of individual, team, and organizational level learning practices has stimulated tremendous interest in the concept of learning organization [12]. Current body of literature suggests that the LO serves as a mechanism that influences an organization's performance through enhanced organizational effectiveness [4], [22], [41] and [1].

In Kenya, logistics have been greatly affected by fierce competitive business environment, rapid changes in technology, increased customer demand as well as globalization of products and services [13]. In addition, some partners in logistics especially clearing and forwarding (C\&F) firms in Kenya seem to have untrained and unethical staff who sometime engage in unprofessional behavior thus affecting the quality of services offered by the said firms [3].
The inexperience can be associated with lack of internal structures and systems to facilitate the continuous learning, knowledge generation, accountability and development of a culture of rapid communication in the organization; factors which have been emphasized by [23], [13] and [39] as being important for a learning organization.

While extant literature depicts the benefits of adopting a LO framework, there are still gaps that call for further exploration. First, the concept has not been much popularized in Africa let alone in Kenya [28] and very little is known about African organizations as learning organizations [27], [20] and [18]. Secondly, scarce empirical evidence exists on continuous improvement and innovation in logistics [7] yet logistics is one of the areas that is currently seeking ways of adding value through innovation and continuous improvement [36]. Thirdly, there exist mixed results on the effect of learning organization. [30] indicates that individual and team level learning factors don't have a direct effect on 
organizational performance while some organization level factors have do not have any significant effect on organizational performance while [33] show that LO negligibly affects performance. Therefore, this study is aimed at determining the effect of learning organization culture on the performance of logistics firms in Mombasa County in Kenya. The objective of this study is to determine how the three levels of learning in a learning organization affect organizational performance. This study is centered in an international logistics company that is a leading market specialist in East and Central Africa with its headquarters in Mombasa.

\section{Literature Review}

\subsection{Theoretical Review}

\subsubsection{Team Climate Theory}

After vast research on group climate and innovation [44] identified three critical conditions (interaction among individuals, shared goals and task interdependence) which facilitate sharing of perceptions at the team level. These conditions are in line with the disciplines of a learning organization i.e. building a shared vision and team learning and systems thinking as suggested by [34].

\subsubsection{Systems and Chaos Theory}

According to [23], open systems and chaos theory help to understand further on how organizational learning differs from individual learning. Open systems and chaos theory are derived from the biological and physical sciences and cannot be applied literally to human systems. Many theorists draw on these theories to explain learning, complexity, and interactivity in organizations. Human systems experience feedback through language and patterns of symbolic communication and relationships. In the open systems model, individual and group leaning are mutually interdependent. Chaotic change is enhanced by a move in organizations to decentralize so that people and units can more easily respond to changes in the environment. Organizations that reflect a chaos model enable free access of knowledge; however, individuals can count on less help from the system in choosing and weighing the ideas that might be of greatest value to an unpredictable future. According to this theory, people learn from what they do, assess outcomes, and adjust their course in alignment with a common vision.

\subsubsection{Transformative Learning Theory}

The term transformation was first applied by [25] in a study of women who were returning to postsecondary learning or the workplace after staying out for a long period. Transformative learning is "the process of effecting changes in a frame of reference [26]. Through reflection, it aims at changing fundamental and conventional assumptions of actions and behaviors into new ones with a new mindset or frame of reference therefore individuals, groups and organizations transform themselves in preparation for organizational change and adaptation.
According to [48] as individuals try to cogenerate new ideas, concepts and processes, following the generative and adaptive process, they become creators of explicit knowledge. Since knowledge is gained because of learning transfer to workplace applications, the process becomes a major contributor to accumulating organization knowledge assets. During transformative learning, individuals re construct the learned knowledge and validation of the individual existing insights that have been adopted by others become collective knowledge. When a learning culture is cultivated in an organization, the organization realizes performance improvement and a positive relationship between a learning organization and performance improvement exists [11]. This therefore enhances the expectation that organizations that nurture a learning organization culture successfully improve organization performance.

\subsection{Conceptual Framework}

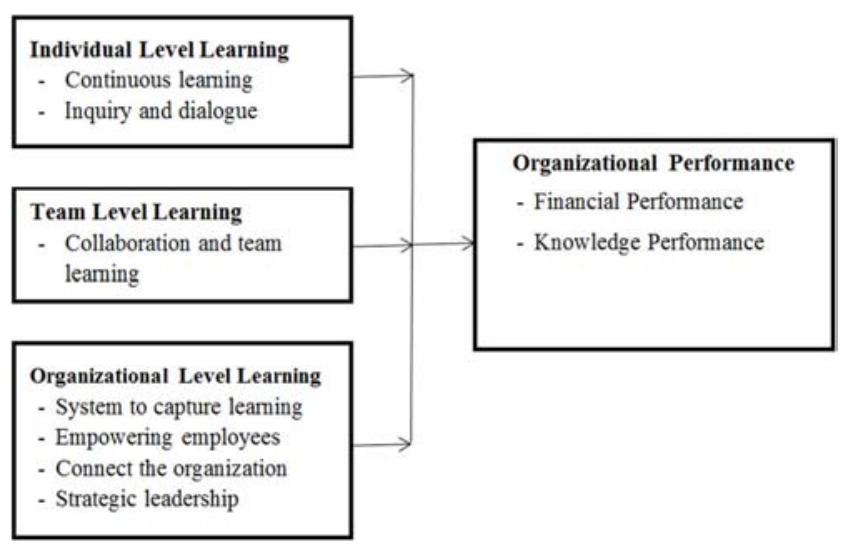

Figure 1. Conceptual Framework.

\subsubsection{Individual Level Learning}

[39] define continuous learning as providing opportunities to learn from the problems that people encounter, using incentives to support both formal and incidental learning and better planning. Continuous learning helps individuals acquire new competencies to be applied on the job. When these individuals are rewarded for learning it creates greater motivation and the individuals become more receptive to learning and develop high self-efficacy [19] that in return improves the individual's performance leading to improved organizational performance.

Inquiry and dialogue is concerned with learning from the experience of others [30]. Dialogue provides a platform for questioning, being open to new ideas and understanding the opinion of other people. It ultimately aids to building a common understanding and cognition among individuals and a shared understanding within the organization [41].

\subsubsection{Team Level Learning}

Organizations have continued to depend on teams to achieve effectiveness through task performance [17]. Through learning together, team members can adapt to changing circumstances, discover new ways of achieving 
team objectives, and continually refine practices and processes leading to discovery of new and better ways of achieving team objectives and realizing team goals, which finally results in a better team performance [5].

[16] developed a three learning behavior model of team learning and performance. They identified the behaviors as tacit coordination, adapting and problem solving. Tacit coordination is the seamless and tacit organization of diverse roles, coordination of knowledge and responsibility in a team. Coordination here focuses on the synchronization of knowledge and skills within a team. Teams with tacit coordination display the ability to organize activities, anticipate the work of other team members, and interact with other team members effectively to achieve team goals. Tacit coordination between and among team members facilitates team processes such as decision making, exchange of information and interpersonal awareness thus enhances team performance. The second behavior is adapting which means responding to internal and external demands through adjusting actions and beliefs. The ability to continuously adapt to the environment allows team members to constantly change strategies and redefine goals in the middle of projects whenever need arise. This behavior keeps the team and organizational performance up to par due to the proactiveness of teams. Problem solving as the last behavior according to [16] involves focusing and addressing problematic activities through collaboration. Collaboration involves channels that foster synchronization of skills and knowledge within the team. It facilitates decision-making, interpersonal awareness and knowledge sharing among team members. The level of performance depends on collaboration and shared interdependence between team members.

\subsubsection{Organizational Level Learning}

At the organizational level, relationships become structured while individual learning and some of the common understandings developed by groups become institutionalized thus organizations are able to change to reflect new knowledge and learning [47].

Organizations find ways to store knowledge and use it to sustain itself during periods of high environmental turbulence and even high staff turnover [41]. To be able to capture, maintain and integrate new information that is useful for improving organizational performance, a system to effectively capture and share learning is required [37]. A good system to capture and share learning can improve organizational performance through people's access to critical knowledge and appropriate information [22]. Learning organizations have a memory to acquire, store, retrieve and manage information and disseminate knowledge through the organization to e.g. new staff members to ensure improved organizational performance [37] and [42].

Another dimension of organizational learning is; empowerment of people towards a collective vision. Employee empowerment means involving employees in decision making by giving them for example, the power in form of e.g. autonomy; information in form of e.g. feedback; knowledge in form of e.g. training and reward in form of for example job enrichment [10]. Empowerment enhances employee's psychological attachment to the organization i.e. commitment. An organizational learning system is supported by a common vision through ways such as keeping people committed to the vision and encouraging them to identify themselves with the vision that promotes organization goals [14]. According to [46], employee empowerment is a powerful management tool and if managed well can cause an increase in performance, productivity and job satisfaction. Through empowerment, employees feel energized and become willing to do whatever it takes to get the work done thus enhancing better performance of the organization [15].

The other dimension is connecting the organization to its environment (or developing system connections). Organizational members here are helped to note the effect of their work on the entire organization, the organization is linked to the community and members often scan the environment and use the information gathered to adjust their work practices [41]. Organizations that take long to heed to environmental changes might end up being left with fewer options if they regain their desired position at all.

The final is strategic leadership whose primary function is to distribute organizational resources in such a way that gives the organization a competitive edge thus rip benefits from the dynamic environment [42]. [29] acknowledge that the vision and mission are one of the most important characteristic of a high performing organization. Developing an organization's vision and the organization's ability to manage change brought about by that vision brings competitive advantage. Strategic leadership is also involved in developing an organization's core competencies. A core competency is an organizational capability to perform in a manner consistently superior to its competitors thus achieving above-average organizational performance [43]. To enhance organizational performance, strategic leadership can influence organizational culture, rituals, symbols, reward systems and boundaries [42]. Here, leadership uses learning strategically to enhance business performance and results [41].

\section{Methodology}

\subsection{Sampling and Procedures}

This study employed stratified and simple random sampling techniques where the population was divided into three strata based on employment level i.e. management, supervisory and subordinate staff. Slovin's formula was used to determine the sample size as below:

$$
\mathrm{n}=\frac{\mathrm{N}}{\left(1+\mathrm{Ne}^{2}\right)}
$$

Where: $\mathrm{n}=$ Sample size, $\mathrm{N}=$ Total population, $\mathrm{e}=$ Error tolerance, 0.05

An online survey was administered and hard copies of questionnaires delivered to those respondents who could not be reached online. The survey questions were designed to 
capture what respondents thought about the presence (or absence) of an effective learning environment in their respective departments. 143 staff from all the staff categories participated in the study yielding a response rate of $78.7 \%$.

A pilot study was conducted and Cronbach Alpha computed where variables that yielded reliability coefficients of 0.70 and above were considered reliable while those that had lower reliability coefficients were deleted or reformulated.

\subsection{Data and Measurement}

Data was collected using the short version of Dimensions of Learning Organization Questionnaire (DLOQ) as refined by [45] and measured the dimensions on a five-point Likert scale (1 - Strongly Disagree, 5-Strongly Agree). Pearson correlation coefficient and Multiple linear regression were used to examine the relationships between dimensions of learning organization and organizational performance. The multiple linear regression model below was used:

$$
\mathrm{Y}=\beta 0+\beta 1 \mathrm{X} 1+\mathrm{B} 2 \mathrm{X} 2+\mathrm{B} 3 \mathrm{X} 3+\varepsilon
$$

Where: $Y=$ Organizational Performance (Dependent Variable), $\beta 0=$ Intercept or constant, $\mathrm{X} 1=$ Individual level learning (Independent Variable), X2 = Team level learning (Independent Variable), X3 = Organizational level learning (Independent Variable).

In the model, $\beta 0=$ the constant term while the coefficient $\beta \mathrm{ii}=1,2 \ldots 7$ will be used to measure the sensitivity of the dependent variable $(\mathrm{Y})$ to unit change in the predictor variables $\mathrm{X} 1, \mathrm{X} 2$ and $\mathrm{X} 3 . \varepsilon$ is the error term which captures the unexplained variations in the model.

\section{Results}

\subsection{Reliability Test}

To determine the reliability of the findings, Cronbach's alpha correlation coefficient was computed at $95 \%$ confidence interval for all the variables under study. Total Cronbach's alpha correlation coefficient was found to be 0.912 , which indicated that the level of internal consistency for the items was 91.2 percent. This showed the existence of acceptable level of inter-item consistency. Dimension-wise reliability was also high.

\subsection{Response Rate}

Out of the total 171 questionnaires that were sent to the respondents, 143 of them were dully filled and returned by the respondents; yielding a response rate of $78.7 \%$.

\subsection{Findings}

\subsubsection{Pearson Correlation Coefficient}

Hypothesis One: Individual level learning does not determine organizational performance.
Table 1. Pearson Correlation Coefficient Matrix.

\begin{tabular}{lll}
\hline Variable & & $\begin{array}{l}\text { Organizational } \\
\text { Performance }\end{array}$ \\
\hline \multirow{2}{*}{ Individual Level } & Pearson Correlation & $.698^{* *}$ \\
Learning & Sig. (2-tailed) & .000 \\
& $\mathrm{~N}$ & 143 \\
Team Level Learning & Pearson Correlation & $.235^{* *}$ \\
& Sig. (2-tailed) & .000 \\
Organization Level & $\mathrm{N}$ & 143 \\
Learning & Pearson Correlation & $.879^{* *}$ \\
& Sig. (2-tailed) & .005 \\
& $\mathrm{~N}$ & 143 \\
\hline
\end{tabular}

As shown in Table 1 below, the p-value was found to be 0.000 which is less than the significant level of 0.05 , $(p<0.05)$. Therefore, the null hypothesis was rejected while the alternative hypothesis was accepted. The result indicated that Pearson Correlation coefficient (r-value) is 0.698 , which represented an average positive relationship between individual level learning and organizational performance.

Hypothesis Two: Team level learning does not determine organizational performance.

As shown in Table 1 below, the p-value was found to be 0.005 which is less than the significant level of 0.05 , $(\mathrm{p}<0.05)$. Therefore, the null hypothesis was rejected while the alternative hypothesis was accepted. The result indicated that Pearson Correlation coefficient (r-value) is 0.235 , which represented a positive but weak relationship between team learning and organizational performance.

Hypothesis Three: Organizational level learning does not determine organizational performance.

As shown in Table 1 below, the p-value was found to be 0.000 which is less than the significant level of 0.05 , $(p<0.05)$. Therefore, the null hypothesis was rejected while the alternative hypothesis was accepted. The result indicated that Pearson Correlation coefficient (r-value) is 0.879 , which represented a positive and strong relationship between Organizational level learning and organizational performance.

\subsubsection{Regression Analysis}

Multiple linear regressions were computed at 95 percent confidence interval (0.05 margin error). Based on the model summary, the coefficient of determination ( $R$ squared) shows the proportion of variance in the dependent variable that can be explained by in the independent variables. It is the overall measure of strength of association between independent and dependent variable. In line with this, 0.880 was found to be the coefficient of determination indicating a strong positive association between independent and dependent variable. $\mathrm{R}$ is the square root of $\mathrm{R}$ squared and it shows the relationship between observed and predicted values of dependent variable; organizational performance. $\mathrm{R}$ is 0.774 shows a strong positive correlation between observed and predicted values of dependent variable; organizational performance. Table 2 shows the findings of the study. 
Table 2. Model Summary.

\begin{tabular}{llll}
\hline Model & R & R Square & Adjusted R Square \\
\hline 1 & $.880^{\mathrm{a}}$ & .774 & .769 \\
\hline
\end{tabular}

a. Predictors: (Constant), Individual level learning, Team level learning, Organization level learning

Table 3 below shows the analysis of variance (ANOVA) of the regression model. The p-value was found to be 0.000 , which is less than 0.05 at 3 degrees of freedoms. This indicates that, the overall regression model statistically significantly predicts the outcome variable and all the model coefficients are significantly different from 0.0 . Therefore, the study concluded that learning organization culture significantly affects organizational performance.

Table 3. Anova ${ }^{a}$.

\begin{tabular}{lllllll}
\hline Model & & Sum of Squares & df & Mean Square & F & Sig. \\
\hline \multirow{2}{*}{1} & Regression & 1855.753 & 3 & 618.584 & 158.442 \\
& Residual & 542.680 & 139 & 3.904 & \\
& Total & 2398.434 & 142 & & \\
\hline
\end{tabular}

a. Dependent Variable: Organizational Performance

b. Predictors: (Constant), Individual level learning, Team level learning, Organization level learning

The findings of the study were regressed on a linear model to establish the relationship between the dependent and independent variable as shown on table 4. Based on the findings of the study, the regression equation model for the study is:

Organizational Performance $=30.494+0.049$ Individual Level Learning +0.141 Team Level Learning +0.412 Organizational Level Learning.
In addition, coefficients for the following variables; Team Level Learning and Organizational Level Learning were found to significant variables since their significant values 0.025 and 0.000 respectively were less than the $p$-value (0.05). However, coefficients for Individual Level Learning was found to be insignificant since its significant values was found to be 0.771 .

Table 4. Coefficients ${ }^{a}$.

\begin{tabular}{|c|c|c|c|c|c|c|}
\hline \multirow{2}{*}{\multicolumn{2}{|c|}{ Model }} & \multicolumn{2}{|c|}{ Non Standard Coefficients } & \multirow{2}{*}{$\begin{array}{l}\text { Standardized Coefficients } \\
\text { Beta }\end{array}$} & \multirow{2}{*}{$\mathbf{t}$} & \multirow{2}{*}{ Sig. } \\
\hline & & B & Std. Error & & & \\
\hline \multirow{4}{*}{1} & (Constant) & 30.494 & 1.646 & & 18.521 & .000 \\
\hline & Individual Level Learning & .049 & .169 & .034 & .292 & .771 \\
\hline & Team Level Learning & .141 & .197 & .053 & .720 & .025 \\
\hline & Organizational Level Learning & .412 & .040 & .893 & 10.355 & .000 \\
\hline
\end{tabular}

a. Dependent Variable: Organizational Performance

\subsection{Discussion of Findings}

This research was set to establish the effect of learning organization culture on the performance of Logistics organizations in Mombasa County. The specific objectives of the study were to establish whether the three levels of learning i.e. individual level of learning, team level learning and organizational level learning affected organizational performance among logistics firms in Mombasa County.

The first objective of the study was to determine the effect of individual level learning on organizational performance. Individual level learning was measured by two sub variables i.e. continuous learning and inquiry and dialogue. The results indicated a positive but weak relationship between continuous learning and organizational performance in consistency with the findings of [41], [47] and [35]. Inquiry and dialogue was found to have a positive and strong relationship with organizational performance in consistency with the findings of [41], [6], [32] and [30]. The overall Pearson correlation coefficient represented an average positive relationship between individual level learning and organizational performance.
The second objective of the study was to determine the effect of team level learning on organizational performance. Team level learning was measured using one sub variable i.e. collaboration and team learning. The results of Pearson Correlation coefficient represented a positive but weak relationship between team level learning and organizational performance. The findings of the study were similar to the findings of [41].

The third objective of the study was to determine the effect organizational level learning on organizational performance. Organizational level learning was measured using four sub variables i.e. embedded systems, employee empowerment, systems connection, and strategic leadership. The results indicated a positive and strong relationship between embedded systems and organizational performance in consistency with the findings of [35] and [22]. Employee empowerment had a positive but average relationship with organizational performance also supported by previous researchers [38], [42] and [8]. Systems connection had a positive and strong relationship with organizational performance in consistency with the findings of [22] and 
[31]. Strategic leadership had a positive and strong relationship with organizational performance in consistency with the findings of [38], [42] and [9]. The overall Pearson correlation coefficient represented a positive and strong relationship between Organizational level learning and organizational performance.

\section{Further Research}

The study concluded that there was a positive but weak relationship between continuous learning, collaboration and team learning, and organisational performance, a positive and average relationship between employee empowerment, embedded systems, organizational performance, and a positive and strong relationship between systems connection, strategic leadership, Inquiry and dialogue and organizational performance. This means that the dimensions of the learning advocated for by the learning organization culture literature, are not by themselves strong enough to influence perceived changes in performance (knowledge and financial performance). This clearly suggests that the journey towards superior performance is highly complex.

Certainly, there are several other variables that better explain financial outcomes. However, the results of this study suggest an important potential relationship between the seven dimensions of learning and perceived changes in knowledge and financial performance. Future studies should be based on hard measures of financial and knowledge performance. Secondly, the data used in the present study is cross-sectional meaning that the variables have been measured at one point of time. Therefore, it is not clear how long a change in the leaning culture can take before it can have an influence in the perceptions of employees and thereby influencing organizational performance. Future research is therefore required to measure the variables over a long period and establish how long it takes before changes in learning can lead to changes in performance.

\section{References}

[1] Ambula, R., Awino, Z. B., and Obonyo, P. K. (2016). Learning Organization and Performance of Large Manufacturing Firms. DBA Africa Management Review, 6 (1), 94-106.

[2] Appelbaum, S. H., \& Goransson, L. (1997). Transformational and adaptive learning within the learning organization: a framework for research and application. The Learning Organization, 4 (3), 115-128.

[3] Arnold, J., Mathenge, J., Dihel, N., and Strychacz, N. (2011, June 13). Africa Trade Policy Notes: The Role of Clearing and Forwarding Agents in Reforming the EAC Logistics Sector. Retrieved February 15, 2016, from World Bank: http://go.worldbank.org/ZSFPC2UF80

[4] Brown, M., and Brudney, J. (2003). Learning organizations in the public sector? A study of police agencies employing information and technology to advance knowledge. Public Administration Review, 63 (1), 30-43.
[5] Bunderon, J. S., \& Sutcliffe, K. M. (2003). Management Team Learning Orientation and Business Unit Performance. Journal of Applied Psychology, 88 (3), 552-560.

[6] Calantone, R. J., Cavusgil, S. T., \& Yushan, Z. (2002). Learning orientation, firm innovation capability, and firm performance. Industrial Marketing Management, 31 (6), 515524.

[7] Caniels, M. C., Kooistra, W., and Semeijn, J. (2008). Proceedings of presentation papers, the 5th international conference on innovation and Management. In ICIM Organizing Committee (Ed.), Drivers and Obstacles for Innovation in Logistics (pp. 857-871). Wuhan: Wuhan University of Polytechnology Publishing House.

[8] Capra, F. (1996). The Web of Life: A New Scientific Understanding of Living Systems. New York: Anchor Doubleday.

[9] Carter, S. M., \& Greer, C. R. (2013). Strategic Leadership. Values, Styles and Organizational Performance. Journal of Leadership \& Organizational Studies, 20 (4), 375-393.

[10] Demirci, M. K., and Erbas, A. (2010). Employee Empowerment and Its Effect on Organizational Performance. 2nd International Symposium on Sustainable Development, (pp. 142-146). Sarajevo.

[11] Ellinger, A. D., Ellinger, A. E., Yang, B., \& Howton, S. W. (2002). The relationship between the learning organization concept and firms' financial performance: An empirical assessment. Human Resource Development Quarterly, 13 (1), $5-21$.

[12] Ellinger, A. D., Yang, B., and Ellinger, A. E. (2000). Is the Learning Organization for Real? Examining the Impacts of the Dimensions of the Learning Organization on Organizational Performance. Adult Education Research Conference (pp. 1-8). Kansas: New Prairie Press.

[13] Fang, S. C., and Wang, J. F. (2006). Effects of organizational culture and learning on manufacturing strategy selection: an empirical study. International Journal of Management, 23, 503-514.

[14] Garvin, D. A., Edmondson, A. C., and Gino, F. (2008). Is yours a learning organization? Harvard Business Review, 83 (3), 109-116.

[15] Ibua, M. P. (2014). The Influence of Institutional Factors and Job Related Attitudes on the Relationship between Employee Empowerment and Performance of Public Universities in Kenya. Unpublished Phd Thesis, University of Nairobi.

[16] Kayes, C., and Burnett, G. (2006). Team Learning in Organizations: A Review and Integration. Organization Learning, Knowledge and Capabilities 2006 Conference (pp. 1-29). Coventry, UK: University of Warwick.

[17] Klein, K., Knight, A., Ziegert, J., Lim, B., \& Saltz, J. (2011). When team members' values differ: the moderating role of team leadership. Organizational Behavior and Human Decision Processes, 114 (1), 25-36.

[18] Kumar, N., \& Idris, K. (2006). An Examination of Educational Institutions' Knowledge Performance: Analysis, Implication and Outlines for Future Research. The Learning Organization, 13 (1), 96-116. 
[19] Laatikainen, E. (2014). Employees Continuous Learning and Job Satisfaction - Effects on Productivity (Unpublished Master's Thesis). Lappeenranta, Finland: Lappeenranta University of Technology.

[20] Lien, L., Yang, B., and Li, Y. L. (2002). An examination of psychometric properties of the Chinese version of the DLOQ in Taiwan. In T. M. Egan (Ed.), Academy of Human Resource Development Conference Proceedings (pp. 854-861). Bowling Green, OH: Academy of Human Resource Development.

[21] Lim, D. H. (2000). Training design factors influencing transfer of training to the workplace within an international context. Journal of Vocational Education and Training, 52 (2), 243257.

[22] Lipshitz, R., Friedman, V. J., and Popper, M. (2007). Demystifying Organizational Learning. Thousand Oaks, CA: Sage.

[23] Marsick, V. J. (2000). Learning Organizations. In V. J. Marsick, J. Bitterman, and R. VanDerVeen, From the Learning Organization to Learning Communities: Torward a Learning Society (pp. 5-20). Columbus: Center on Education and Training for Employment Center Publications.

[24] Meyerson, G., and Dewettinck, B. (2012). Effect of Empowerment on Employees Performance. Advanced Research in Economic and Management Sciences, 2, 40-46.

[25] Mezirow, J. (1978a). Education for Perspective Transformation: Women's re-entry Programs in Community Colleges. New York: Teacher's College, Columbia University.

[26] Mezirow, J. (2012). Learning to think like an adult: Core concepts of transformation theory. In E. Taylor, \& P. Cranton (Eds.), The Handbook of Transformative Learning: Theory, Research and Practise (pp. 73-96). San Francisco, CA: Jossey-Bass.

[27] Ngesu, L., Wambua, L. B., Ndiku, J., \& Mwaka, M. (2008). Universities as learning organizations: Implications and Challenges. Education Research and Review, 3 (9), 289-293.

[28] Nzuve, S. N., \& Omolo, E. A. (2012). A study of the practice of the learning organization and its relationship to performance in Kenyan Commercial Banks. Problems of Management in the 21st Century, 4, 45-56.

[29] Pazireh, M., Akhlagh, E. M., \& Akbari, M. (2014). Evaluation the Role of Strategic Leadership in Organizational Performance. Universal Journal of Management and Social Sciences, 4 (9), 23-28.

[30] Pokharel, M. P., \& Choi, S. O. (2015). Exploring the relationships between the learning organization and organizational performance. Management Research Review, $38(2), 126-148$.

[31] Porter, M. E., \& Kramer, M. (2006). Strategy and society: the link between competitive advantage and corporate social responsibility. Harvard Business Review, 1 (1), 78-92.

[32] Ramus, C. A., \& Steger, U. (2000). The Role of Supervisory Support Behaviors and Environmental Policy in Employee 'Ecoinitiatives' at Leading Edge European Companies. The Academy of Management Journal, 43 (4), 605-626.

[33] Ratna, R., Khanna, K., Jogishwar, N., Khattar, R., \& Agarwal,
R. (2014). Impact of Learning Organization on Organizational Performance in Consulting Industry. International Journal on Global Business Management and Research, 2 (2), 1-11.

[34] Senge, P. M. (2006). The fifth discipline: The art and practice of the learning organization (2nd Edition ed.). New York: Currency Doubleday.

[35] Song, J. h., Joo, B. K., \& Chermack, T. J. (2009). The Dimensions of LO Questionnaire (DLOQ): a validation study in a Korean context. Human Resource Development Quarterly, 20 (1), 43-64.

[36] Soosay, C. A., \& Hyland, P. W. (2004). Driving Innovation in Logistics: Case Studies in Distribution Centers. Creativity \& Innovation Management, 13 (1), 41-51.

[37] Tippins, M. J., \& Sohi, R. S. (2003). IT competency and firm performance: is organizational learning a missing link? Strategic Management Journal, 24 (8), 745-761.

[38] Vera, D., \& Crossan, M. (2004). Strategic leadership and organizational learning. Academy of Management Review, 29 (1), 222-240.

[39] Vijjuprabha, D. (2015). The Guidelines for the Development of Logistics Learning Organization. International Journal of the Computer, the Internet and Management, 23 (2), 65-69.

[40] Watkins, K. E., \& Marsick, J. V. (1993). Sculpting the Learning Organization: Lessons in the Art and Science of Systemic Change. San Francisco, CA: Jossey-Bass.

[41] Watkins, K. E., \& Marsick, V. J. (2003). Making Learning Count! Diagnosing the Learning Culture in Organizations. Thousand Oaks, CA: Sage.

[42] Weldy, T. (2009). Learning organization and transfer: strategies for improving performance. The Learning Organization, 16 (1), 58-68.

[43] Wendy, L. (2012). The relationship between strategic leadership and strategic alignment in high perfomancing companies in South Africa. Unpublished PHD Thesis, University of South Africa.

[44] West, M. A., \& Farr, J. L. (1990). Innovation and creativity at work: psychological and organisational strategies. Chichester: Wiley.

[45] Yang, B., Watkins, K., \& Marsick, V. (2004). The construct of the learning organization: dimensions, measurement, and validation. Human Resource Development Quarterly, 150 (5), 31-55.

[46] Yang, S.-B., \& Choi, S. O. (2009). Employee empowerment and team performance: Autonomy, responsibility, information, and creativity. Team Performance Management: An International Journal, 15 (5/6), 289-301.

[47] Yang, Y. (2012). Bilateral inter-organizational learning in corporate venture capital activity governance characteristics, knowledge transfer, and performance. Management Research Review, 35 (5), 352-378.

[48] Yoon, S. W., Song, J. H., \& Lim, D. H. (2009). Beyond the Learning Process and Toward the Knowledge Creation Process: Linking Learning and Knowledge in the Supportive Learning Culture. Performance Improvement Quarterly, 22 (3), 49-69. 